\title{
More than vital: Who bears the burden?
}

\author{
Dawn S. Hui, MD, and Richard Lee, MD, MBA
}

\author{
From the Center for Comprehensive Cardiovascular Care, St Louis University, St Louis, Mo. \\ Disclosures: Authors have nothing to disclose with regard to commercial support. \\ Received for publication Sept 20, 2016; accepted for publication Sept 21, 2016; available ahead of print Nov 17, \\ 2016. \\ Address for reprints: Richard Lee, MD, MBA, Center for Comprehensive Cardiovascular Care, 3635 Vista Ave, \\ DT 13F, St Louis, MO 63110 (E-mail: rlee@slu.edu). \\ J Thorac Cardiovasc Surg 2017;153:902-3 \\ $0022-5223 / \$ 36.00$ \\ Copyright $(2) 2016$ by The American Association for Thoracic Surgery \\ http://dx.doi.org/10.1016/j.jtcvs.2016.09.081 \\ "Pray, Mr. Babbage, if you put into the machine \\ wrong figures, will the right answers come out?" I \\ am not able rightly to apprehend the kind of \\ confusion of ideas that could provoke such a question.
}

-Charles Babbage

In 2012, Dr Blackstone sounded the warning on the disappearance of the US Social Security Administration's Death Master File as a publicly available research tool for vital status. ${ }^{1}$ The Death Master File, also known as the Social Security Death Index (SSDI), is considered sensitive and specific, although admittedly less accurate than the more costly and less timely National Death Index (NDI). Since November 1, 2011, protected state death records have been removed as a data source for the SSDI. In this issue of the Journal, Peterss and colleagues ${ }^{2}$ found that, compared with an alternative method of vital status determination, use of SSDI data overestimated the long-term survival of patients after aortic and aortic valve surgery. Because they report the estimated survival difference during the entire study period of 2000 to 2015, it is difficult to ascertain the relative contribution of the SSDI change to the inaccuracy.

As mentioned previously, the SSDI has been considered to have adequate sensitivity and specificity, such that it has played a role in a number of high-quality cardiothoracic surgery studies ranging from risk algorithm prediction to the impact of surgical techniques and perioperative medication ${ }^{1}$; however, it is still not considered a gold standard for vital status determination. The completeness of the SSDI was shown to be in the range of $94 \%$ to $96 \%$ for patients older than 65 years of age. ${ }^{3}$ A more recent study, predating the 2011 change, showed accuracy rates as low as $79.8 \%$, with age, sex, nonwhite race, and nonmalignancy etiology being risk factors for inaccuracy. ${ }^{4}$

The brief communication by Peterss and colleagues ${ }^{2}$ demonstrates not only the importance of the SSDI change in a granular way, but it raises the broader issue of vital status determination in cardiothoracic surgical outcomes. This endpoint is one whose methodology is often taken for granted. In our informal review of the last 3 issues of The Journal, 21 studies reported long-term survival in the inflict?

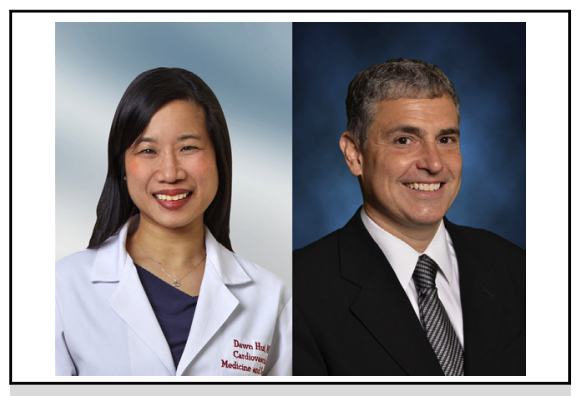

Dawn S. Hui, MD, and Richard Lee, MD, MBA

Central Message

Often overlooked, vital status determination methodology and accuracy have been further affected by changes in Social Security Death Index. Critical assessments of survival data should account for these data quality issues.

See Article page 899.

results section. Of these, 10 lacked a description of the vital status determination methodology. Interestingly, Dr Blackstone himself was a senior author on one of these papers. Of the remainder, there was a wide variation in the method (and thus also validity), ranging from simply "telephone questionnaire/call" $(\mathrm{n}=2)$ to a multimodal assessment $(n=4)$, similar to the one Peterss and colleagues ${ }^{2}$ conducted. Three reported use of the SSDI supplemented by other means. Only one reported use of the NDI.

This finding suggests that greater scrutiny and improved description of vital status determination methods are needed. As long the NDI remains cost-prohibitive, the burden remains on researchers to find alternative methods that are accurate. It is not a light burden. The multimodal method of Peterss and colleagues, ${ }^{2}$ involving 5 sequential steps, is labor and resource intensive. The irony is that in an age of increasing layperson access (or at least the appearance of such) to medical evidence and research via consumer-oriented Web sites, those who are most invested and in the best position to educate, counsel, and guide patients to better outcomes are being further handicapped. Until such time as a reliable, accurate, and accessible source of vital status becomes available, it will unfortunately remain the burden of both cardiac surgeons and their patients to deal with these uncertainties. As the SSDI change was not prompted by Health Insurance Portability and Accountability Act or privacy concerns, 2 questions remain: what public good does it serve, and what public harm does it 


\section{References}

1. Blackston EH. Demise of a vital resource. J Thorac Cardiovasc Surg. 2012;143: 37-8.

2. Peterss S, Charilaou P, Ziganshin BA, Eleftriades JA. Assessment of survival in retrospective studies: the Social Security Death Index is not adequate for estimation. J Thorac Cardiovasc Surg. 2017;153:899-901.

3. Hill ME, Rosenwaike I. The Social Security Administrations' Death Master File the completeness of death reporting at older ages. Soc Secur Bull. 2001-2002;64: $45-51$.

4. Huntington JT, Butterfield M, Fisher J, Torrent D, Bloomston M. The Social Security Death Index (SSDI) most accurately reflects true survival for older oncology patients. Am J Cancer Res. 2013;3:518-22. 